\title{
NGHIÊN CỨU NHÂN GIỐNG IN VITRO VÀ NUÔI TRỒNG CÂY LAN GẤM (ANOECTOCHILUS LYLEI ROLFE EX DOWNIES) Ở ĐIỀU KIỆN EX VITRO
}

\author{
Phan Xuân Huyên ${ }^{a^{*}}$, Nguyễn Văn Kết ${ }^{b}$, Phan Hoàng Đại ${ }^{c}$, Nguyễn Thị Cúc \\ ${ }^{a}$ Viện Nghiên cúu Khoa học Tây Nguyên, \\ Viện Hàn lâm Khoa họ và Công nghệ Việt Nam, Lâm Đồng, Việt Nam \\ ${ }^{b}$ Khoa Nông Lâm, Trường Đại học Đà Lạt, Lâm Đồng, Việt Nam \\ 'Viện Nghiên cưu và Úng dụng Nông nghiệp Công nghệ cao, Trường Đại học Đà Lạt, \\ Lâm Đồng, Việt Nam \\ Lịch sử bài báo \\ Nhận ngày 20 tháng 07 năm 2016 | Chỉnh sửa ngày 30 tháng 08 năm 2016 \\ Chấp nhận đăng ngày 15 tháng 09 năm 2016
}

\begin{abstract}
Tóm tắt
Trong nghiên cứu này, chúng tôi nghiên cứu nhân giống in vitro và nuôi trồng loài Anoectochilus lylei Rolfe ex Downies ở điều kiện ex vitro, là một loại thảo duợc quí và tốt cho sức khỏe của con người. Kết quả cho thấy, môi truờng MS bổ sung $1 \mathrm{mg} / \mathrm{l}$ BA là tốt nhất đến sụ tái sinh chồi in vitro sau 60 ngày nuôi cấy, với số chồi 5,70 chồi/mẫu, chiều cao chồi 3,72 cm. Môi truờng MS bổ sung $0-2 \mathrm{mg} / \mathrm{l}$ NAA đều thích hợp đến sự tái sinh rễ in vitro sau 30 ngày nuôi cẩy, với tỉ lệ tái sinh rễ 100\%. Chuyến cây lan gấm in vitro ra điều kiện ex vitro, giá thể $90 \%$ vun xo dù̃a phối trộn $10 \%$ tro trấu là tốt nhất đến sư thích nghi của cây con sau 60 ngày nuôi trồng, với chiều cao cây $7,00 \mathrm{~cm}$, chiều dài rề $4,74 \mathrm{~cm}$ và tỉ lệ sống đạt $100 \%$. Nuôi trồng cây lan ở điều kiện ex vitro, sau 120 ngày nuôi trồng, phun phân Nitrophoska ${ }^{\circledR}$ Foliar với nồng độ $2 \mathrm{~g} / \mathrm{l}$ (chiều cao cây đạt 11,00 cm, chiều dài rễ $7,60 \mathrm{~cm}$, khối luợng tuơi $1,81 \mathrm{~g} / \mathrm{cây}$, tỉ lệ sống đạt 100\%) tốt hơn nồng độ $1 \mathrm{~g} / \mathrm{l}$ (chiều cao cây đạt 9,80 cm, chiều dài rễ $6,70 \mathrm{~cm}$, khối lựng tuoi 1,64 g/cây, tỉ lệ sống đạt 100\%).
\end{abstract}

Từ khóa: Cây lan gấm; Giá thể; Phân bón; Sự tái sinh chồi; Sự tái sinh rễ.

\section{GIỚI THIỆU}

Tây Nguyên có điều kiện tự nhiên phù hợp với nhiều loài thực vật quí hiếm sinh trưởng và phát triển. Trong đó, cây lan gấm (Anoectochilus lylei Rolfe ex Downies) là một loại thảo dược quí, có tác dụng chữa bệnh, tăng cường sức khỏe cho con người và có giá trị kinh tế (Phùng, Nguyễn, \& Nguyễn, 2010; Trần và ctg., 2015; Đỗ và ctg., 2015). Hiện nay, nạn phá rừng làm nương rẫy làm cho khu phân bố của cây lan gấm ngày càng thu hẹp, thêm vào đó, con người thu hái lan gấm một cách tận diệt từ cây non đến cây trưởng thành, dẫn đến nguồn lan gấm trong tự nhiên ngày càng giảm dần và có nguy cơ tuyệt chủng cao (Phùng và ctg., 2010; Nguyễn \& Phí, 2012). Vì vậy, việc

\footnotetext{
*Tác giả liên hệ: Email: phanxuanhuyen1974@gmail.com
} 
nghiên cứu nhân giống và nuôi trồng cây lan gấm với mục đích bảo tồn và phát triển nguồn gen thảo dược quí, tạo ra nguồn nguyên liệu phục vụ cho lĩnh vực thực phẩm, mỹ phẩm và y học là vấn đề rất cần thiết.

Hiện nay, trên thế giới và trong nước đã có nhiều công bố nghiên cứu nhân giống in vitro các loài lan gấm có giá trị dược liệu như: loài Anoectochilus formosaus (Du và ctg., 2008; Yoon và ctg., 2007; Nguyen và ctg., 2004), loài Anoectochilus setaceus (Nguyen \& Phi, 2012; Đỗ và ctg., 2015; Tran và ctg., 2015), loài Anoectochilus roxburghii (Phùng và ctg., 2010; Trương \& Phan, 2013), đối với loài Anoectochilus lylei, chỉ mới thấy một công bố của Phan và ctg. (2015) nghiên cứu nhân giống in vitro. Việc nuôi trồng cây lan gấm ở giai đoạn ex vitro, trên thế giới đã có công bố nhưng vẫn còn ít (Gangaprasad \& Seeni, 2000; Cheng \& Chang, 2009; Chang, Chou \& Lee, 2007; Nguyen, 2003; Shiau và ctg., 2002). Ở nước ta chưa thấy công bố nào nghiên cứu nuôi trồng cây lan gấm ở giai đoạn ex vitro. Do đó, chúng tôi tiến hành nghiên cứu nhân giống và nuôi trồng loài Anoectochilus lylei. Kết quả của nghiên cứu này góp phần xây dựng qui trình nhân giống in vitro và nuôi trồng ở điều kiện ex vitro loài Anoectochilus lylei.

\section{VẬT LIỆU VÀ PHƯƠNG PHÁP NGHIÊN CÚU}

\subsection{Vật liệu}

Tiến hành thu hái cây lan gấm mọc tự nhiên tại Vườn Quốc gia Chư Yang Sin, tỉnh Đắk Lắk (Hình 1a), mẫu được rửa sạch bằng nước xà phòng, sau đó khử trùng bằng cồn $70^{\circ}$ trong 1 phút, cuối cùng khử trùng bằng dung dịch $\mathrm{HgCl}_{2} 0,1 \%$ trong 8 phút. Mẫu sau khi khử trùng xong được cắt thành các đốt và cấy trên môi trường $\mathrm{MS}$ (Murashige \& Skoog, 1962) bổ sung $1 \mathrm{mg} / \mathrm{l} \mathrm{BA}$ (6-benzyl adenin), 10\% nước dừa, $1 \mathrm{~g} / \mathrm{l}$ than hoạt tính, 30 g/l sucrose, 8 g/l agar, pH 5,8 (Nguyen và ctg., 2004). Những chồi non tái sinh từ các đốt thân (Hình $1 \mathrm{~b}$ ) được dùng làm nguồn vật liệu cho các thí nghiệm.

\subsection{Phương pháp nghiên cứu}

\subsubsection{Môi truờng và điều kiện nuôi cấy}

Môi trường nuôi cấy là MS, tùy theo mục đích của các thí nghiệm mà bổ sung 
các chất kích thích sinh trưởng BA, NAA, chuối (chuối mốc chín), than hoạt tính, sucrose và agar. Đối với thí nghiệm in vitro, thời gian chiếu sáng 10 giờ/ngày, cường độ ánh sáng $34 \mu \mathrm{mol} \cdot \mathrm{m}^{-2} \cdot \mathrm{s}^{-1}$, nhiệt độ $25 \pm 2^{\circ} \mathrm{C}$ và độ ẩm không khí $75-85 \%$. Thí nghiệm ở điều kiện ex vitro, giá thể là vụn xơ dừa, tro trấu, phân Nitrophoska ${ }^{\circledR}$ Foliar $(\mathrm{N}: 25 \%$, $\mathrm{P}_{2} \mathrm{O}_{5}: 10 \%, \mathrm{~K}_{2} \mathrm{O}: 17,5 \%$, Fe: 0,050\%, Zn: 0,019\%, Mn: 0,050\%, B: 0,011\%, $\mathrm{Cu}:$ $0,019 \%$, Mo: 0,001$)$. Vườn ươm có mái che mưa và che lưới đen chắn $80-85 \%$ ánh sáng, nhiệt độ $20-25^{\circ} \mathrm{C}$, độ ẩm $80-85 \%$.

\subsubsection{Bố trí thí nghiệm}

- Thí nghiệm 1: Khảo sát ảnh hưởng của $\mathrm{BA}$ đến sự tái sinh chồi in vitro: Những đốt thân in vitro (Hình $1 \mathrm{~b}$ ) được cấy trên môi trường MS bổ sung 0 ; 0,$1 ; 0,5 ; 1 ; 1,5 ; 2 \mathrm{mg} / 1 \mathrm{BA}, 50 \mathrm{~g} / \mathrm{l}$ chuối, $30 \mathrm{~g} / \mathrm{l}$ sucrose, $1 \mathrm{~g} / \mathrm{l}$ than hoạt tính, $8 \mathrm{~g} / \mathrm{l}$ agar, pH 5,8. Mỗi nghiệm thức cấy 30 mẫu, sau 60 ngày nuôi cấy tiến hành thu số liệu. Chỉ tiêu theo dõi là chiều cao chồi $(\mathrm{cm})$, số chồi/mẫu.

- Thí nghiệm 2: Khảo sát ảnh hưởng của NAA đến sự tái sinh rễ in vitro: Những chồi ngọn in vitro (Hình $1 \mathrm{~b}$ ) đồng đều về chiều cao được cấy trên môi trường MS bổ sung $0 ; 0,5 ; 1 ; 1,5 ; 2$ và $3 \mathrm{mg} / \mathrm{l} \mathrm{NAA}, 30 \mathrm{~g} / \mathrm{l}$ sucrose, 8 $\mathrm{g} / \mathrm{l}$ agar, $1 \mathrm{~g} / \mathrm{l}$ than hoạt tính, pH 5,8. Mỗi nghiệm thức cấy 30 mẫu, sau 60 ngày nuôi cấy tiến hành thu số liệu. Chỉ tiêu theo dõi là số rễ/mẫu, chiều dài rễ $(\mathrm{cm})$ và tỉ lệ tạo rễ (\%).

- Thí nghiệm 3: Khảo sát ảnh hưởng của giá thể đến sự thích nghi của cây in vitro ở điều kiện ex vitro: Những cây lan gấm in vitro đồng đều về chiều cao và chiều dài rễ được trồng trên giá thể $100 \%$ vụn xơ dừa, giá thể $90 \%$ vụn xơ dừa phối trộn $10 \%$ tro trấu, giá thể $80 \%$ vụn xơ dừa phối trộn $20 \%$ tro trấu và giá thể $70 \%$ vụn xơ dừa phối trộn $30 \%$ tro trấu. Mỗi nghiệm thức trồng 30 cây, sau 60 ngày nuôi trồng tiến hành thu số liệu. Chỉ tiêu theo dõi là chiều cao cây $(\mathrm{cm})$, chiều dài rễ $(\mathrm{cm})$ và tỉ lệ sống $(\%)$.

- Thí nghiệm 4: Khảo sát ảnh hưởng của phân bón lá Nitrophoska ${ }^{\circledR}$ Foliar đến sự sinh trưởng của cây ở điều kiện ex vitro: Từ kết quả của thí nghiệm trước 
chọn giá thể thích hợp nhất đến sự thích nghi của cây in vitro để thực hiện thí nghiệm này. Vật liệu thí nghiệm là những cây lan gấm đã thích nghi ở điều kiện ex vitro. Phân bón lá được sử dụng là Nitrophoska ${ }^{\circledR}$ Foliar với nồng độ $1 \mathrm{~g} / \mathrm{l}$ và $2 \mathrm{~g} / \mathrm{l}$, phun định kỳ mỗi tuần một lần. Mỗi nghiệm thức trồng 30 cây, sau 120 ngày nuôi trồng tiến hành thu số liệu. Chỉ tiêu theo dõi là chiều cao cây $(\mathrm{cm})$, chiều dài rễ $(\mathrm{cm})$, khối lượng tươi/cây $(\mathrm{g})$ và tỉ lệ sống (\%).

\subsection{Xử lý số liệu}

Số liệu của các thí nghiệm được xử lý bằng phần mềm thống kê SPSS (bản 15.0) trong Duncan's test và T-test (Duncan, 1955), với mức độ tin cậy $P<0,05$.

\section{KẾT QUẢ VÀ THẢO LUẬN}

\subsection{Khảo sát ảnh hưởng của $\mathrm{BA}$ đến sự tái sinh chồi in vitro}

Khả năng tái sinh chồi từ đốt thân sau 60 ngày nuôi cấy được thể hiện trên Bảng 1. Kết quả cho thấy, BA có ảnh hưởng tích cực đến sự tái sinh chồi, tuy nhiên ở những nồng độ khác nhau thì có sự tái sinh chồi khác nhau. Chồi cây ở những môi trường có bổ sung chất kích thích sinh trưởng mọc nhiều lông hút, trong khi đó, chồi cây ở môi trường không có chất kích thích sinh trưởng thì không có (Hình $1 \mathrm{c}_{1}, 1 \mathrm{c}_{2}, 1 \mathrm{c}_{3}, 1 \mathrm{c}_{4}, 1 \mathrm{c}_{5}$, $1 \mathrm{c} 6$ ). Môi trường bổ sung $1 \mathrm{mg} / \mathrm{l} \mathrm{BA}$ tái sinh chồi nhiều nhất, với số chồi 5,70 chồi/mẫu, chiều cao chồi $3,72 \mathrm{~cm}$. Khi tăng nồng độ $B A$ từ $0-1 \mathrm{mg} / \mathrm{l}$ thì số chồi và chiều cao chồi tăng lên, nhưng khi nồng độ BA tăng lên $1,5-2 \mathrm{mg} / \mathrm{l}$ thì số chồi và chiều cao chồi giảm xuống, chồi cây có màu xanh nhạt và yếu. Điều này cho thấy, khi nồng độ BA thấp thì kích thích sự tái sinh chồi và tăng trưởng chiều cao chồi, nhưng khi nồng độ BA tăng cao thì xảy ra quá trình ngược lại. So sánh với các kết quả đã công bố thì kết quả của thí nghiệm này tương đồng với kết quả nghiên cứu của Nguyen và ctg. (2004) khi nghiên cứu nhân giống in vitro loài Anoectochilus formosaus, kết quả cho thấy, BA ở nồng độ $1 \mathrm{mg} / \mathrm{l}$ tái sinh chồi cao nhất là 5,10 chồi/mẫu. Nguyễn và Phí (2012) nghiên cứu nhân giống in vitro loài Anoectochilus setaceus cũng có kết quả tương tự, khi BA ở nồng độ 1 $\mathrm{mg} / \mathrm{l}$ thì tái sinh chồi nhiều nhất là 5,22 chồi/mẫu. Nhưng kết quả của nghiên cứu này 
thấp hơn kết quả của Phan và ctg. (2015) khi nghiên cứu loài Anoectochilus lylei, BA ở nồng độ $15 \mu \mathrm{M} / 1$ có số chồi tái sinh nhiều nhất là 9,12 chồi/mẫu.

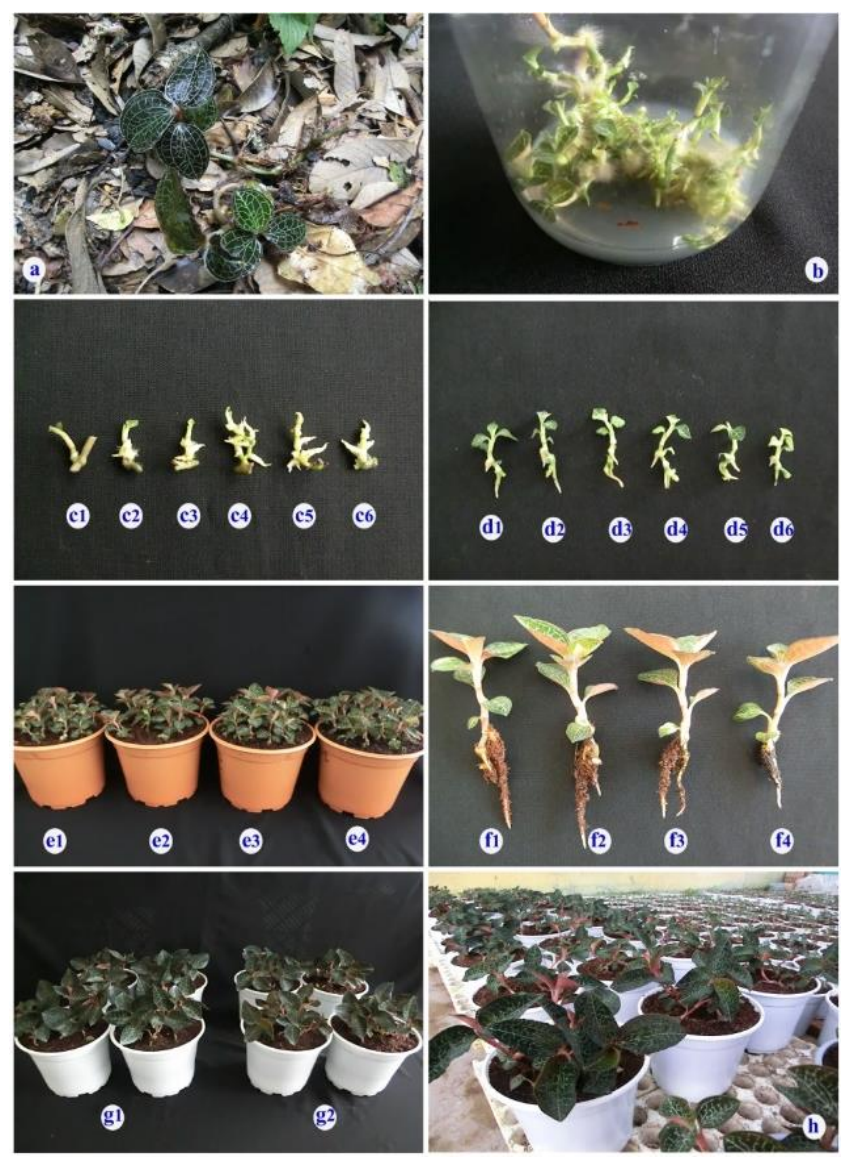

\section{Hình 1. Nghiên cứu nhân giống và nuôi trồng cây lan gấm (Anoectochilus lylei)}

Ghi chú: (a) Cây lan gấm có nguồn gốc từ Vườn Quốc gia Chư Yang Sin, Đắk Lắk; (b) Chồi tái sinh từ đốt thân; $\mathrm{c}_{1}, \mathrm{c}_{2}, \mathrm{c}_{3}, \mathrm{c}_{4}, \mathrm{c}_{5}, \mathrm{c}_{6}$. Tái sinh chồi trên môi trường $0,0,1,0,5,1,1,5,2 \mathrm{mg} / \mathrm{BA} ; \mathrm{d}_{1}, \mathrm{~d}_{2}, \mathrm{~d}_{3}, \mathrm{~d}_{4}, \mathrm{~d}_{5}$ $\mathrm{d}_{6}$. Tái sinh rễ trên môi trường $0,0,5,1,1,5,2,3 \mathrm{mg} / \mathrm{l} \mathrm{NAA} ; \mathrm{e}_{1}, \mathrm{e}_{2}, \mathrm{e}_{3}, \mathrm{e}_{4}$ và $\mathrm{f}_{1}, \mathrm{f}_{2}, \mathrm{f}_{3}, \mathrm{f}_{4}$. Cây lan gấm trồng trên giá thể $100 \%$ vụn xơ dừa, $90 \%$ vụn xơ dừa $+10 \%$ tro trấu, $80 \%$ vụn xơ dừa $+20 \%$ tro trấu, $70 \%$ vụn xơ dừa $+30 \%$ tro trấu; $\mathrm{i}_{1}, \mathrm{i}_{2}$. Cây lan gấm phun phân Nitrophoska ${ }^{\circledR}$ Foliar với nồng độ $2 \mathrm{~g} / \mathrm{l}$ và $1 \mathrm{~g} / \mathrm{l} ; \mathrm{h}$.

Nuôi trồng cây lan gấm.

Bảng 1. Ảnh hưởng của BA đến sự tái sinh chồi in vitro sau 60 ngày nuôi cấy

\begin{tabular}{ccc}
\hline BA $(\mathrm{mg} / \mathrm{l})$ & Số chồi/mẫu & Chiều cao chồi $(\mathrm{cm})$ \\
\hline 0,0 & $1,50^{\mathrm{e}^{*}}$ & $2,65^{\mathrm{c}}$ \\
0,1 & $2,40^{\mathrm{d}}$ & $2,72^{\mathrm{c}}$ \\
0,5 & $3,60^{\mathrm{c}}$ & $2,98^{\mathrm{b}}$ \\
1,0 & $5,70^{\mathrm{a}}$ & $3,72^{\mathrm{a}}$ \\
1,5 & $4,80^{\mathrm{b}}$ & $3,58^{\mathrm{a}}$ \\
2,0 & $2,80^{\mathrm{d}}$ & $2,90^{\mathrm{b}}$ \\
\hline
\end{tabular}


Ghi chú: *Những mẫu tự khác nhau (a, b, c, d, e) được nêu trong cột biểu diễn sự khác nhau có ý nghĩa với $\mathrm{P}<0,05$ trong Duncan's test.

Như vậy, môi trường MS bổ sung $1 \mathrm{mg} / \mathrm{l}$ BA là tốt nhất đến sự tái sinh chồi in vitro của loài Anoectochilus lylei.

\subsection{Khảo sát ảnh hưởng của NAA đến sự tái sinh rễ in vitro}

Khả năng tái sinh rễ in vitro của những chồi ngọn được thể hiện trên Bảng 2. Kết quả cho thấy, tất cả các chồi cây ở môi trường không có chất kích thích sinh trưởng và môi trường có chất kích thích trưởng đều tái sinh rễ, với tỉ lệ $100 \%$, điều này cho thấy cây lan gấm là một đối tượng dễ dàng tái sinh rễ in vitro. Tuy nhiên, ở những môi trường khác nhau thì sự tái sinh rễ có sự khác nhau, môi trường bổ sung 1 mg/l NAA có số rễ nhiều nhất (3,00 rễ/mẫu).

Theo số liệu thì ở môi trường bổ sung $1 \mathrm{mg} / \mathrm{l}$ NAA có chiều dài rễ dài nhất $(1,46$ $\mathrm{cm})$, nhưng theo xử lý thông kê thì chiều dài rễ ở môi trường có bổ sung $0,5 \mathrm{mg} / \mathrm{l} \mathrm{NAA}$ $(1,40 \mathrm{~cm})$ và $1 \mathrm{mg} / \mathrm{l}$ NAA không có sự khác biệt. Khi nồng độ NAA tăng $0-1 \mathrm{mg} / \mathrm{l}$ thì số rễ, chiều dài rễ tăng lên và cây sinh trưởng tốt (Hình $\left.1 \mathrm{~d}_{1}, 1 \mathrm{~d}_{2}, 1 \mathrm{~d}_{3}\right)$, nhưng khi nồng độ NAA tăng $1,5-3 \mathrm{mg} / \mathrm{l}$ thì số rễ, chiều dài rễ giảm xuống. Cây in vitro trên môi trường bổ sung 1,5 và $2 \mathrm{mg} / 1 \mathrm{NAA}$ sinh trưởng tốt (Hình $1 \mathrm{~d}_{4}, 1 \mathrm{~d}_{5}$ ), nhưng ở môi trường $3 \mathrm{mg} / \mathrm{l}$ sinh trưởng kém, có màu xanh nhạt và yếu không thích hợp khi chuyển cây ra điều kiện ex vitro (Hình 1d6).

Kết quả của thí nghiệm này tương dương với kết quả nghiên cứu của Nguyen (2003) khi nghiên cứu tạo rễ in vitro loài Anoectochilus formosaus, đã cho thấy, tất cả chồi cây ở môi trường không có chất kích thích sinh trưởng đều tái sinh rễ 100\%, với số rễ 2,00 rễ/mẫu, khi NAA ở nồng độ $1 \mathrm{mg} / 1$ thì số rễ tái sinh nhiều nhất, với số rễ 4,80 rễ/mẫu. Nguyễn và ctg. (2012) cũng nghiên cứu tái sinh rễ in vitro loài Anoectochilus setaceus, kết quả cho thấy, tất cả mẫu ở môi trường không có chất kích thích sinh trưởng cũng đều tái sinh rễ 100\%, khi môi trường bổ sung $1 \mathrm{mg} / \mathrm{l}$ NAA thì số rễ tái sinh nhiều nhất, với 4,21 rễ/mẫu. Trương và Phan (2013) nghiên cứu tái sinh rễ in vitro loài Anoectochilus roxburghii, kết quả cho thấy, khi NAA ở nồng độ $0,3 \mathrm{mg} / 1$ thì tái sinh rễ đạt $100 \%$ và số rễ tái sinh nhiều nhất là 3,10 rễ/mẫu. Trong khi đó, Phan và ctg. (2015) 
nghiên cứu tái sinh rễ in vitro loài Anoectochilus lylei cho kết quả tái sinh rễ cao nhất chỉ đạt $89,72 \%$ khi NAA ở nồng độ $0,5 \mu \mathrm{M} / 1$, với số rễ tái sinh là 2,02 rễ/mẫu.

Như vậy, nồng độ NAA từ $0-2 \mathrm{mg} / 1$ đều phù hợp sự tái sinh rễ in vitro loài Anoectochilus lylei.

Bảng 2. Ảnh hưởng của NAA đến sự tái sinh rễ in vitro sau 30 ngày nuôi cấy

\begin{tabular}{cccc}
\hline NAA $(\mathrm{mg} / \mathrm{l})$ & Số rễ/mẫu & Chiều dài rễ $(\mathrm{cm})$ & Tỉ lệ tạo rễ $(\%)$ \\
\hline 0,0 & $2,00^{\mathrm{b} *}$ & $1,32^{\mathrm{ab}}$ & 100 \\
0,5 & $2,40^{\mathrm{ab}}$ & $1,40^{\mathrm{a}}$ & 100 \\
1,0 & $3,00^{\mathrm{a}}$ & $1,46^{\mathrm{a}}$ & 100 \\
1,5 & $2,80^{\mathrm{a}}$ & $1,35^{\mathrm{ab}}$ & 100 \\
2,0 & $2,50^{\mathrm{ab}}$ & $1,21^{\mathrm{b}}$ & 100 \\
3,0 & $2,10^{\mathrm{b}}$ & $1,00^{\mathrm{c}}$ & 100 \\
\hline
\end{tabular}

Ghi chú: *Những mẫu tự khác nhau $(\mathrm{a}, \mathrm{b}, \mathrm{c})$ được nêu trong cột biểu diễn sự khác nhau có ý nghĩa với $\mathrm{P}<$ 0,05 trong Duncan's test.

\subsection{Khảo sát ảnh hưởng của giá thể đến sự thích nghi của cây in vitro ở điều kiện ex vitro}

Khả năng thích nghi của cây con sau 60 ngày nuôi trồng được thể hiện trên Bảng 3. Nghiên cứu chuyển cây in vitro ra điều kiện ex vitro là một công đoạn quan trọng quyết định thành công trong nuôi cấy mô thực vật, cây con in vitro thường nuôi cấy trên môi trường thạch khi chuyển ra điều kiện $e x$ vitro bộ rễ phải thích nghi trên giá thể mới. Hơn nữa, độ ẩm trong điều kiện in vitro cao hơn và ổn định hơn ở môi trường ex vitro, dẫn đến cây con thường bị héo và chết. Vì vậy, trong thời gian đầu cần phải che chắn và phun sương giữ ẩm cho cây. Kết quả cho thấy, tỉ lệ sống của cây con trên các giá thể đều đạt $100 \%$, cây con đã thích nghi và sinh trưởng tốt (Hình $1 \mathrm{e}_{1}, 1 \mathrm{e}_{2}, \mathrm{e}_{3}, 1 \mathrm{e}_{4}$ ). Điều này có thể giải thích giá thể vụn xơ dừa và vụn xơ dừa phối trộn với tro trấu có độ thoáng và giữ ẩm thích hợp cho cây con thích nghi và sinh trưởng. Theo số liệu thì chiều cao cây trồng trên các loại giá thể có sự khác nhau, nhưng theo xứ lý thống kê thì không có sự khác biệt. Rễ của cây con sinh trưởng tăng chiều dài, trên bề mặt của rễ mọc nhiều lông hút bám chặc giá thể (Hình $1 \mathrm{f}_{1}, 1 \mathrm{f}_{2}, 1 \mathrm{f}_{3}, 1 \mathrm{f}_{4}$ ). Giá thể $90 \%$ vụn xơ dừa phối trộn $10 \%$ tro trấu có chiều dài rễ dài nhất $(4,74 \mathrm{~cm})$, khi tăng hàm lượng tro trấu 20 - 30\% thì chiều dài rễ giảm xuống, tương ứng 3,36 và 2,92 cm và ngắn hơn rễ của cây 
trồng trên giá thể $100 \%$ vụn xơ dừa $(4,47 \mathrm{~cm})$, điều này có thể giải thích khi tăng hàm lượng của tro trấu thì ức chế sự tăng trưởng chiều dài của rễ. Ở nước ta hiện nay đã có nhiều công bố nhân giống in vitro các loài lan gấm, nhưng nghiên cứu chuyển cây in vitro ra điều kiện ex vitro thì chưa thấy công bố nào đề cập. Kết quả của nghiên cứu này cũng tương đồng với kết quả của Nguyễn và ctg. (2004) khi nghiên cứu chuyển cây in vitro của loài Anoectochilus formosanus ra điều kiện ex vitro có tỉ lệ sống đạt $100 \%$ sau 4 tuần nuôi cấy.

Bảng 3. Ảnh hưởng của giá thể đến sự thích nghi của cây in vitro ở điều kiện ex vitro sau 60 ngày nuôi trồng

\begin{tabular}{lccc}
\hline Giá thể & Chiều cao cây $(\mathrm{cm})$ & Chiều dài rễ $(\mathrm{cm})$ & Tỉ lệ sống $(\%)$ \\
\hline $100 \%$ vụn xơ dừa & $6,98^{\mathrm{a}^{*}}$ & $4,47^{\mathrm{b}}$ & 100 \\
$90 \%$ vụn xơ dừa $+10 \%$ tro trấu & $7,00^{\mathrm{a}}$ & $4,74^{\mathrm{a}}$ & 100 \\
$80 \%$ vụn xơ dừa $+20 \%$ tro trấu & $7,00^{\mathrm{a}}$ & $3,36^{\mathrm{c}}$ & 100 \\
$70 \%$ vụn xơ dừa $+30 \%$ tro trấu & $6,97^{\mathrm{a}}$ & $2,92^{\mathrm{d}}$ & 100 \\
\hline
\end{tabular}

Ghi chú: *Những mẫu tự khác nhau $(\mathrm{a}, \mathrm{b}, \mathrm{c}, \mathrm{d})$ được nêu trong cột biểu diễn sự khác nhau có ý nghĩa với $\mathrm{P}<0,05$ trong Duncan's test.

Một nghiên cứu khác của Nguyen (2003) đã sử dụng giá thể xơ dừa phối trộn với than mùn và giá thể xơ dừa phối trộn với đá trân châu để chuyển cây in vitro của loài Anoectochilus formosanus ra điều kiện ex vitro. Bên cạnh đó, Shiau và ctg. (2002) đã nghiên cứu sử dụng giá thể rêu than bùn chuyển cây in vitro loài Anoectochilus formosanus ra điều kiện ex vitro, kết quả cho thấy tỉ lệ sống của cây đạt $90 \%$ sau 2 tháng nuôi trồng.

Như vậy, giá thể $90 \%$ vụn xơ dừa phối trộn $10 \%$ tro trấu là giá thể thích hợp nhất để chuyển cây in vitro của loài Anoectochilus lylei ra điều kiện ex vitro.

\subsection{Khảo sát ảnh hưởng của phân Nitrophoska ${ }^{\circledR}$ Foliar đến sự sinh trưởng của cây ở điều kiện $e x$ vitro}

Từ kết quả của thí nghiệm trước chọn giá thể $90 \%$ vụn xơ dừa phối trộn $10 \%$ tro trấu để thực hiện thí nghiệm này. Khả năng sinh trưởng của cây sau 120 ngày nuôi trồng được thể hiện trên Bảng 4. Kết quả cho thấy, tỉ lệ sống của cây ở các nghiệm thức đều đạt $100 \%$ và cây sinh trưởng tốt (Hình $1 g_{1}, 1 g_{2}$ ). Tuy nhiên, sự sinh trưởng của cây ở 
các nghiệm thức khác nhau thì có sự khác nhau, nghiệm thức phun phân Nitrophoska ${ }^{\circledR}$ Foliar với nồng độ $2 \mathrm{~g} / \mathrm{l}$ (chiều cao cây $11,00 \mathrm{~cm}$, chiều dài rễ $7,60 \mathrm{~cm}$, khối lượng tươi $1,81 \mathrm{~g} / \mathrm{cây}$ ) tốt nhất hơn ở nông độ $1 \mathrm{~g} / 1$ (chiều cao cây $9,80 \mathrm{~cm}$, chiều dài rễ $6,70 \mathrm{~cm}$, khối lượng tươi 1,64 g/cây). Vào mùa khô độ ẩm không khí xuống thấp ảnh hưởng đến sự sinh trưởng của cây, do đó cần phải phun sươn liên tục đảm bảo độ ẩm cho cây. Trong mùa khô xuất hiện nhiều sâu cắn phá lan gấm, sâu con có chiều dài khoảng 0,5 $1 \mathrm{~cm}$ chỉ hút nhựa lá, làm cho lá bị khô và hèo, khi sâu có kích thước lớn hơn thì không hút nhựa lá nhưng lại cắn phá thân cây. Phun thuốc trừ sâu sinh học AMECTIN AIC 36 EC (3 ml/l) định kỳ một tháng một lần và kết hợp với hàng ngày quan sát bắt sâu là một phương pháp rất hiệu quả trong phòng và trị sâu hại trên cây lan gấm. Vào mùa mưa thì ít sâu hại hơn, nhưng có nấm xuất hiện làm hư lá lan gấm hơn mùa khô, tuy nhiên không nhiều. Phun thuốc nấm Kasuran 47WP $(3 \mathrm{~g} / 1)$ theo định kỳ $1-2$ tháng một lần để phòng ngừa và trị nấm bệnh trên cây lan gấm. Ngoài ra, trong nuôi trồng cây lan gấm có hiện tượng tại vị trí đốt thân trên mặt đất bị khô làm gãy đứt cây lan gấm hay rễ khí sinh tại đốt thân bị hư cũng làm gãy đứt cây lan gấm. Phần gốc của cây lan gấm mọc ra $1-2$ chồi mới, phần ngọn giâm trên giá thể trong điều kiện độ ẩm thích hợp sẽ tái sinh rễ và tạo thành một cây lan gấm mới tiếp tục sinh trưởng.

Hiện nay ở nước ta chưa thấy công bố nào nuôi trồng cây lan gấm ở điều kiện $e x$ vitro, kết quả của thí nghiệm này tương đồng với một số kết quả đã công bố trên thế giới như: Nguyen (2003) nghiên cứu nuôi trồng loài Anoectochilus formosanus, sau 5 tháng nuôi trồng kết quả cho thấy, khối lượng tươi của cây khoảng 2,0 - 2,7 g/cây, chiều cao của cây khoảng $8,5-10,1 \mathrm{~cm}$; Chang và ctg. (2007) cũng nghiên cứu nuôi trồng loài Anoectochilus formosanus theo phương pháp mới là đặt chậu lan gấm trong túi nylon, kết quả sau 4 tháng nuôi trồng cho thấy, cây nuôi trồng theo phương pháp mới trong túi nylon có chiều cao là $8,1 \mathrm{~cm}$, khối lượng tươi $1,8 \mathrm{~g}$, trong khi đó, cây nuôi trồng theo phương pháp thông thường thì chiều cao cây chỉ đạt $6,3 \mathrm{~cm}$, khối lượng tươi 1,6 g; Cheng và Chang (2009) cũng nghiên cứu nuôi trồng loài Anoectochilus formosanus ở độ cao $1.000 \mathrm{~m}$ so với mực nước biển, sau 7 tháng nuôi trồng kết quả cho thấy, khối lượng tươi đạt $5-6 \mathrm{~g} / \mathrm{cây}$, chiêu cao cây $8-9 \mathrm{~cm}$; Bên cạnh đó, Shiau và ctg. (2002) cũng nghiên cứu nuôi trồng loài Anoectochilus formosanus trong buồng sinh 
trưởng; Gangaprasad và ctg. (2000) nghiên cứu nuôi trồng loài Anoectochilus regalis ở môi trường rừng tự nhiên.

Như vậy, trong nuôi trồng loài Anoectochilus lylei sử dụng phân bón lá Nitrophoska ${ }^{\circledR}$ Foliar ở nồng độ $2 \mathrm{~g} / 1$ tốt hơn nồng độ $1 \mathrm{~g} / \mathrm{l}$.

\begin{tabular}{|c|c|c|c|c|}
\hline $\begin{array}{l}\text { Nitrophoska }{ }^{\circledR} \text { Foliar } \\
(\mathrm{g} / \mathrm{l})\end{array}$ & $\begin{array}{l}\text { Chiều cao cây } \\
(\mathrm{cm})\end{array}$ & $\begin{array}{l}\text { Chiều dài rễ̂ } \\
(\mathrm{cm})\end{array}$ & Khối lượng tươi/cây (g) & $\begin{array}{c}\text { Tỉ lệ sống } \\
\text { (\%) }\end{array}$ \\
\hline 1 & $9,80^{\mathrm{b} *}$ & $6,70^{\mathrm{b}}$ & $1,64^{\mathrm{b}}$ & 100 \\
\hline 2 & $11,00^{\mathrm{a}}$ & $7,60^{\mathrm{a}}$ & $1,81^{\mathrm{a}}$ & 100 \\
\hline
\end{tabular}

Ghi chú: *Những mẫu tự khác nhau $(\mathrm{a}, \mathrm{b})$ được nêu trong cột biểu diễn sự khác nhau có ý nghĩa với $\mathrm{P}<$ 0,05 trong T-test.

\section{KẾT LUẬn}

Từ các kết quả nhận được, chúng tôi rút ra kết luận môi trường MS bổ sung 1 mg/l BA, 50 g/l chuối, $30 \mathrm{~g} / 1$ sucrose, 1 g/l than hoạt tính, $8 \mathrm{~g} / \mathrm{l}$ agar, pH 5,8 là tốt nhất đến sự tái sinh chồi in vitro từ đốt thân. Mồi trường MS bổ sung $0-2 \mathrm{mg} / \mathrm{l} \mathrm{NAA}$ đều thích hợp đến sự tái sinh rễ in vitro. Giá thể $90 \%$ vụn xơ dừa phối trộn $10 \%$ tro trấu là tốt nhất để chuyển cây lan gấm in vitro ra điều kiện ex vitro. Trong nuôi trồng loài Anoectochilus lylei sử dụng phân lá Nitrophoska ${ }^{\circledR}$ Foliar với nồng độ 2 g/l tốt hơn 1 g/l.

\section{LÒ̀I CẢM ON}

Các tác giả xin chân thành cảm ơn Sở Khoa học và Công nghệ tỉnh Đắk Lắk, Viện Nghiên cứu Khoa học Tây Nguyên - Viện Hàn lâm Khoa học và Công nghệ Việt Nam đã tạo điều kiện thuận lợi cho chúng tôi hoàn thành nghiên cứu này.

\section{TÀI LIỆU THAM KHẢO}

Chang, D. C. N., Chou, L. C., \& Lee, G. C. (2007). New cultivation methods for Anoectochilus formosanus Hayata. Orchid Science and Biotechnology, 1(2), 5660.

Cheng, S. F., \& Chang, D. C. N. (2009). Growth responses and changes of active components as influenced by elevations and orchid mycorrhizae on Anoectochilus formosanus Hayata. Botanical Studies 50, 459-466.

Duncan, D. B. (1955). Multiple range and F tests. Biometrics, 11, 1-42. 
Du, X. M., Irino N., Uto T., Morinaga O., \& Shoyama Y. (2008). Micropropagation of Anoectochilus formosanus Hayata in vitro and pharmacological and chemical investigations. Phytochemistry, 9, 79-87.

Đỗ, M. C., Vũ, Q. L., Nguyễn, V. C., Nguyễn, T. S., Nguyễn, H. H., Hồ, T. T., Nguyễn, X. T., Trần H., Hoàng, T. T., Nguyễn, T. K .L., \& Dương, T. N. (2015). Ảnh hưởng của một số yếu tố lên quá trình sinh trưởng và phát triển của cây lan gấm (Anoectochilus setaceus Blume) nuôi cấy in vitro. Tạp chí Khoa học và Phát triển, 13(3), 337-344.

Gangaprasad A., Latha, P. G., \& Seeni, S. (2000). Micropropagation of terrestrial orchids, Anoectochilus sikkimensis and Anoectochilus regalis. Indian Journal of Experimental Biology, 38(2), 149-154.

Nguyen, V. K. (2003). Effect of environmental conditions on in vitro and ex vitro growth of jewel orchid (Anoectochilus formosanus Hayata). PhD Thesis of Philosophy in Agriculture, The Graduate School of Chungbuk National University, Korea.

Nguyen, V. K., Hahn, E. J., Park, S. Y., Chakrabarty, D., \& Paek, K. Y. (2004). Micropropagation of an endangered orchid Anoectochilus formosanus Hayata. Biologia Plantarum, 48(3), 339-344.

Murashige, T., \& Skoog, F. (1962). Areivsed medium for rapid growth and bioassays with tobacco tissue. Plant Physiology, 15, 473-497.

Nguyễn, Q. T., \& Phí, T. C. M. (2012). Nghiên cứu kỹ thuật nhân giống loài lan kim tuyến (Anoectochilus cetaceus Blume) in vitro bảo tồn nguồn dược liệu quí. Tạp chí Khoa hoc và Phát triển, 10(4), 579-603.

Pandey, D. M., Yu, K. W., Wu, R. Z., Hahn, E. J., \& Paek, K. Y. (2006). Effects of different irradiances on the photosynthetic process during ex vitro acclimation of Anoectochilus sp. plantlets. Photosynthetica, 44(3), 419-424.

Phùng, V. P., Nguyễn, T. H. G., \& Nguyễn, T. T. (2010). Nghiên cứu kỹ thuật nhân nhanh chồi in vitro loài lan Kim tuyến (Anoectochilus roxburghii (Wall.) Lindl). Tap chí Khoa học ĐHQGHN, Chuyên san Khoa học Tụ nhiên và Công nghệ, 26, 248-253.

Phan, X. B. M., Phạm, H. S., Trần, M. H., \& Nguyễn, T. V. (2015). Nghiên cứu nhân giống nhằm bảo tồn lan sứa (Anoectochilus lylei Rolfe ex Downies). Hội nghị khoa học toàn quốc về sinh thái và tài nguyên sinh vật lần thứ sáu. Hà Nội, Việt Nam: NXB. Khoa học Tự nhiên và Công nghệ.

Shiau, Y. J., Sagare, A. P., Chen, U. C., Yang, S. R., \& Tsay, H. S. (2002). Conservation of Anoectochilus formosanus Hayata by artificial cross-pollination and in vitro culture of seeds. Botanical Bulletin Academia Sinica, 43, 123-130.

Trương, T. B. P., \& Phan, N. K. (2013). Nhân giống in vitro cây lan Kim tuyến (Anoectochilus roxburghii (Wall.) Lindl). Tạp chí Khoa học Đại học Huế, 79(1), 41-46. 
Trần, T. H. T., Đỗ, T. G., Nguyễn, K. H., Phạm, B. N., \& Chu, H. H. (2015). Nghiên cứu nhân nhanh in vitro loài lan Kim tuyến (Anoectochilus setaceus Blume) thông qua cảm ứng tạo protocorm like bodies. Tạp chí Sinh học, 37(1), 67-83.

Wang S. Y., Kuo, Y. H., Chang, H. N., Kang, P. L., Tsay, H. S., Lin, K. F., Yang, N. S., $\&$ Shyur, L. F. (2002). Profiling and characterization antioxidant activities in Anoectochilus formosanus Hayata. Journal of Agricultural and Food Chemistry, 50, 1859-1865.

Yoon, Y. J., Murthy, H. N., Hahn, E. J., \& Paek, K. Y. (2007). Biomass production of Anoectochilus formosanus Hayata in a bioreactor system. Journal of Plant Biology, 50(5), 573-576.

\title{
STUDY ON IN VITRO PROPAGATION AND CULTIVATION OF ANOECTOCHILUS LYLEI ROLFE EX DOWNIES AT EX VITRO CONDITION
}

\author{
Phan Xuan Huyen ${ }^{a^{*}}$, Nguyen Van Ket ${ }^{\mathrm{b}}$, Phan Hoang Daic, Nguyen Thi Cuc ${ }^{\mathrm{b}}$ \\ ${ }^{a}$ Tay Nguyen Institute for Scientific Research, \\ Vietnam Academy of Science and Technology, Vietnam \\ ${ }^{b}$ The Faculty of Agriculture and Forestry, Dalat University, Lamdong, Vietnam \\ ${ }^{b}$ Institute of Research \& High-Tech Application in Agriculture, Dalat University, \\ Lamdong, Vietnam \\ Corresponding author: Email: phanxuanhuyen1974@gmail.com
}

Article history

Received: July $20^{\text {th }}, 2016$ | Received in revised form: August $30^{\text {th }}, 2016$

Accepted: September $15^{\text {th }}, 2016$

\begin{abstract}
In the present study, we investigated in vitro propagation and cultivated Anoectochilus lylei Rolfe ex Downies at ex vitro condition, which is one of the valuable herbal plants and has been proved to be good for human health. The results showed that, MS medium supplemented with $1 \mathrm{mg} / \mathrm{l}$ BA gave the best on in vitro shoot regeneration after 60 days of culture, with 5.70 shoots/explant, shoot height of $3.72 \mathrm{~cm}$. MS medium containing $0-2$ $\mathrm{mg} / \mathrm{l} N A A$ was found to be the most suitable for in vitro root regeneration after 30 days of culture, root regeneration rate of 100\%. Substrate of $90 \%$ coconut fiber powder combination with $10 \%$ rice husk was the best substrate for acclimatization of the plantlet after 60 days of cultivation, with plant height of $7.00 \mathrm{~cm}$, root length of $4.74 \mathrm{~cm}$, survival rate of $100 \%$. For the cultivation of Anoectochilus lylei, after 120 days of cultivation, the result showed that, the plants which were used with Nitrophoska ${ }^{\circledR}$ Foliar of $2 \mathrm{~g} / \mathrm{l}$ (plant height of $11.00 \mathrm{~cm}$, root length of $7.60 \mathrm{~cm}$, fresh weight of $1.81 \mathrm{~g} /$ plant, survival rate of $100 \%$ ) were better than Nitrophoska ${ }^{\circledR}$ Foliar of $1 \mathrm{~g} / \mathrm{l}$ (plant height of $9.80 \mathrm{~cm}$, root length of $6.70 \mathrm{~cm}$, fresh weight of $1.64 \mathrm{~g} /$ plant, survival rate of $100 \%$ ).
\end{abstract}

Keywords: Anoectochilus lylei; Fertilizer; Plant growth; Shoot regeneration; Substrate. 